\title{
O processo de formação de cultura organizacional em um hospital filantrópico
}

\author{
THE PROCESS OF ORGANIZATIONAL CULTURE FORMATION IN APHILANTHROPIC HOSPITAL \\ EL PROCESO DE FORMACIÓN DE LA CULTURA EN UN HOSPITAL FILANTRÓPICO
}

\author{
Valéria Bertonha Machado', Paulina Kurcgant ${ }^{2}$
}

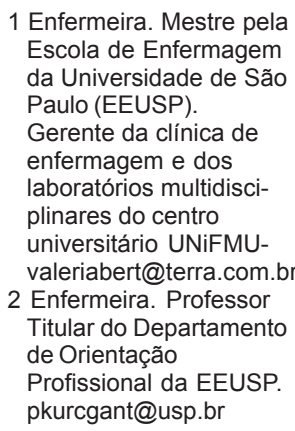

1 Enfermeira. Mestre pela Escola de Enfermagem da Universidade de São Paulo (EEUSP). Gerente da clínica de enfermagem e dos laboratórios multidisciplinares do centro universitário UNiFMUvaleriabert@terra.com.br 2 Enfermeira. Professor Titular do Departamento de Orientação Profissional da EEUSP. pkurcgant@usp.br

\begin{abstract}
RESUMO
Este estudo foi realizado em uma instituição hospitalar de caráter filantrópico, de médio porte, localizada na cidade de São Paulo, com o objetivo de desvendar traços culturais da instituição. A metodologia adotada foi à pesquisa qualitativa segundo os passos propostos por Thévenet: análise documental, entrevista e observação. Pela análise ficou evidenciado que um novo grupo profissional, quando inserido em uma instituição, considera que alguns valores deverão ser transformados. Esse processo de mudança implica numa reestruturação na maneira de gerir a organização ocasionando, nos sujeitos que estão vivenciando esse processo, uma situação conflituosa entre o mudar ou conservar o antigo.
\end{abstract}

\section{PALAVRAS-CHAVE}

Cultura.

Mudança organizacional. Instituições Filantrópicas de Saúde.

Organizações.

\begin{abstract}
This study was carried out in a philanthropic mediumsize hospital institution in Sao Paulo-Brazil, aiming to disclose the cultural features of the institution. The adopted methodology was the qualitative study, following the steps proposed by Thévenet: document analysis, interview and observation. The analysis showed that when a new professional group starts working in an institution, it considers that some values must be changed. This change means to restructure the management of the organization and the people involved in it, facing the conflict posed by changing or preserving the old system.
\end{abstract}

\section{KEYWORDS}

Culture.

Organization innovation.

Philanthropic health

institutions.

Organizations.

\section{RESUMEN}

Este estudio fue realizado en una institución hospitalaria de carácter filantrópico, de medio porte, situada en la ciudad de Sao Paulo con el objetivo de desvendar trazos culturales de la institución. La metodología adoptada fue la investigación cualitativa según los pasos propuestos por Thévenet: análisis documental, entrevista y observación. A través del análisis quedó evidente que un nuevo grupo profesional, cuando está insertado en una institución, considera que alguno de los valores deben ser transformados. Ese proceso de cambio implica en una reestructuración en la manera de gerenciar la organización ocasionando, en los sujetos que están vivenciando ese proceso, una situación conflictiva entre el cambiar o conservar lo antiguo.

\section{PALAVRAS CLAVE}

Cultura.

Innovación organizacional. Agencias voluntarias de salud.

Organizaciones. 


\section{INTRODUÇÃO}

O capital humano de toda organização em funcionamento tem características próprias e coletivas na sua forma de pensar e agir e com as quais convive habitualmente, no cotidiano do trabalho. As formas de pensar, as condutas, os símbolos que dão significado ao concreto fazem parte da chamada cultura organizacional.

Cultura organizacional é o conjunto de pressupostos básicos que um grupo inventou, descobriu ou desenvolveu ao aprender como lidar com os problemas de adaptação externa e integração interna e que funcionaram bem o suficiente para ser considerado válido e ensinado a novos membros como a forma correta de perceber, pensar e sentir, em relação a esses problemas ${ }^{(1)}$.

Fleury ${ }^{(2)}$ partindo da concepção de Schein incorporou, ao conceito de cultura, o aspecto político definindo-a como o conjunto de valores e pressupostos básicos expressos em elementos simbólicos, que em sua capacidade de ordenar, atribuir significações, construir a identidade organizacional, age tanto como elemento de comunicação e consenso, como oculta e instrumentaliza as relações de dominação.

É um desafio para qualquer gerente descortinar traços culturais que permeiam o cotidiano de um grupo ao qual não pertence. O que causa impacto, muitas vezes, é a uniformidade de comportamentos de seus membros, que assimilam uma linha de pensamento e, a partir daí, constroem o seu espaço de atuação. Essa maneira uniforme de perceber a organização é denominada de identidade cultural.

No presente estudo, estaremos evidenciando o processo de expansão da área física e a complexidade do desenvolvimento de uma organização hospitalar de caráter filantrópico, de médio porte que se destina a atender, prioritariamente, crianças carentes portadoras de deficiência física.

Um dos fatores que levou a administração, bem como os profissionais da área de saúde a sentir necessidade de ampliar a infra - estrutura física para oferecer um atendimento globalizado ao deficiente físico (Centro de Diagnóstico, Centro de Tratamento, Centro de Reabilitação), decorreu das sucessivas crises econômicas do país que influenciaram, diretamente, as políticas sociais, levando à falência os programas de saúde pública. Em decorrência dessas crises, tem ocorrido ao longo dos anos uma crescente demanda de pacientes provenientes do próprio município, de outros estados brasileiros bem como provenientes de outros países da América Latina.

Em 1994, foi inaugurado o hospital com a finalidade de oferecer suporte ao atendimento realizado nos ambulatórios que, anteriormente, só contavam com o Centro de Reabilitação.

Com a expansão da área física e principalmente devido ao grau de complexidade dos procedimentos ali realizados, deflagraram-se conflitos entre as diferentes culturas profissionais existente na organização.

Nesta organização, atuam médicos de diferentes especialidades, psicólogos, fisioterapeutas, enfermeiros, terapeutas ocupacionais, assistentes social, fonoaudiólogos, engenheiros, nutricionistas, farmacêutico, odontólogos, professoras, psicopedagogas, administrador, contabilista, profissional de marketing, técnico em informática, técnicos em órteses e próteses, corpo de voluntariado e pessoal de apoio que atua na limpeza, lavanderia, manutenção.

O objetivo deste estudo é analisar a cultura do Serviço de Enfermagem, desvelando as crenças e valores que permeiam o vivencial dos profissionais dessa área, que vão de encontro ás diferentes subculturas profissionais que compõem o universo organizacional.

\section{METODOLOGIA}

$\mathrm{Na}$ a realização do estudo foi adotada a vertente da pesquisa qualitativa. Para o recolhimento do material de base, utilizou -se o referencial teórico segundo a abordagem de Thévenet ${ }^{(3)}$; análise documental (documentos sobre o passado, relativos às normas elaboradas pela organização como, planos da empresa, procedimentos orçamentais, estratégias traçadas para atingir as metas propostas); documentos de informação: como jornais e filmes da organização; como também balanço financeiro e social, entrevistas, observação, e estudos.

Vale ressaltar que o resultado da coleta de informações não é demonstrativo da
O processo de formação de cultura organizacional em um hospital filantrópico 
Valéria Bertonha Machado Paulina Kurcgant cultura da empresa, mas sim, um conjunto de traços que exprimem as crenças, os valores e os pressupostos básicos que são cultivados pela organização.

Os sujeitos do estudo foram selecionados pelos critérios antiguidade, nível hierárquico e diversidade profissional. Foram entrevistadas quatro enfermeiras que ocupam cargo de chefia (Gerente de Enfermagem, Enfermeira chefe do Centro Cirúrgico, Enfermeira responsável pela Educação Continuada, Enfermeira que atua na área de custos). Também, responderam às entrevistas o diretor clínico, o médico responsável pela supervisão hospitalar, e dois médicos ortopedistas responsáveis pela clínica de mielomeningocele, que ocupavam esses cargos durante a realização do estudo.
Para a coleta do material de base, segundo a análise documental, foram lidas as atas da Assembléia Geral desde a data da fundação da organização até os dias atuais, bem como analisados os artigos publicados em jornais da imprensa oficial e também artigos de circulação interna sobre a organização.

A história de vida profissional do fundador e a da empresa foram reconstruídas, oralmente, pela narração dos profissionais que conviveram com o fundador e ainda atuavam na organização e pela leitura dos diversos documentos analisados. Dessa maneira, pode-se construir a grade de informações que relacionam os depoimentos e a análise documental com os traços culturais expressos. (vide Quadro 1).

Quadro 1 - Grade de informações construída a partir do recolhimento do material de base

\begin{tabular}{|c|c|c|}
\hline Item & Informações recolhidas & Indicadores \\
\hline $\begin{array}{l}\text { História } \\
\text { do } \\
\text { Fundador }\end{array}$ & $\begin{array}{l}\text { - Tinha um ideal que para muitos não passava } \\
\text { de um sonho impossível. } \\
\text {-Utilizava contatos com as pessoas influentes e } \\
\text { poderosas para tornar realidade o seu sonho. } \\
\text { - Detinha vasto conhecimento médico e } \\
\text { centralizava as decisões na sua pessoa. } \\
\text { - Buscava sempre a tecnologia de ponta e a } \\
\text { especialização dos profissionais que atuavam } \\
\text { na instituição. } \\
\text { - Comandava todas as ações. } \\
\text { - Empreendia lutas essenciais para tornar a vida } \\
\text { do deficiente físico menos dura. }\end{array}$ & $\begin{array}{l}\text { Idealista } \\
\text { Estrategista } \\
\text { Centralizador } \\
\text { Busca pela excelência } \\
\text { Autoritário } \\
\text { Empreendedor }\end{array}$ \\
\hline $\begin{array}{l}\text { História da } \\
\text { Instituição }\end{array}$ & $\begin{array}{l}\text { - Focada no cliente; no atendimento global; na } \\
\text { reabilitação; na educação; na inserção } \\
\text { profissional no mercado de trabalho e no } \\
\text { ajustamento social. } \\
\text { - Morte do Fundador - considerado um incidente } \\
\text { crítico. } \\
\text { O substituto, por não ser médico e desconhecer } \\
\text { várias áreas de atuação da instituição, solicita a } \\
\text { colaboração de todos, numa forma de gestão } \\
\text { mais participativa. } \\
\text { - Inauguração do Hospital - Oficina Ortopédica } \\
\text { - Os profissionais da área técnica* têm possi- } \\
\text { bilidade de aprimoramento e atualização nos } \\
\text { melhores centros do mundo. } \\
\text { - Expansão da área física com aumento do } \\
\text { quadro de pessoal e aumento da complexidade } \\
\text { dos procediemnto. Inserção de novos profissio- } \\
\text { nais vindos do mercado com uma nova visão. } \\
\text { Incidente crítico }\end{array}$ & $\begin{array}{l}\text { Traço cultural - Valorização do deficiente físico } \\
\text { como um ser humano global. } \\
\text { Traço cultural - Nova forma de gestão } \\
\text { convocando todos a participarem, ativamente, } \\
\text { na continuidade da obra iniciada pelo fundador. } \\
\text { Observou-se, com isto, um melhor desempenho } \\
\text { no ano subseqüente com o aumento da receita e } \\
\text { a diminuição das despesas. } \\
\text { Traço cultural - Valorização da dimensão } \\
\text { técnico-científica, bem como das atividades } \\
\text { acadêmicas. } \\
\text { Traço cultural - Valorização da capacitação da } \\
\text { equipe multiprofissional. } \\
\text { Traço cultural - Esta expansão foi relatada por } \\
\text { muitos entrevistados como sendo traumática e } \\
\text { dramática. Estão buscando, através de uma } \\
\text { consultoria externa, formas de resolver os } \\
\text { problemas, principalmente de comunicação, } \\
\text { entre área técnica e área administrativa. }\end{array}$ \\
\hline Profissão & $\begin{array}{l}\text { - Os profissionais que ocupam cargo de } \\
\text { comando na área técnica, são profissionais } \\
\text { competentes em sua área de atuação, } \\
\text { "nascidos" e "criados" na própria instituição, com } \\
\text { formação complementar no exterior e com } \\
\text { características pessoais e profissionais que } \\
\text { comungam com os mesmos valores } \\
\text { institucionais. }\end{array}$ & $\begin{array}{l}\text { Traço cultural - Valorização do profissional } \\
\text { competente, sendo este traço característico da } \\
\text { área de comando técnico. } \\
\text { Valorização da origem e da tradição. }\end{array}$ \\
\hline
\end{tabular}

* área técnica - termo utilizado para denominar os profissionais que prestam assistência direta ao paciente 
O resgate de alguns traços da instituição proporcionaram a análise dos campos de forças que permitem avaliar os acontecimentos de uma organização num dado momento. Para tanto, foram consideradas as forças impulsionadoras e restritivas do ambiente interno que influenciaram no desempenho da organização e traçadas linhas de ação, segundo a proposta da teoria da mudança de Kurt Lewin apud Bateman e Snell(4).

O modelo adotado para a entrevista teve como base as propostas de Schein ${ }^{(1)}$ acrescido de perguntas que tinham, por finalidade, esclarecer pontos ainda obscuros dos documentos e registros estudados. Assim, foram questões do estudo:

1) Quais foram os problemas críticos do arranque?

2) Quais os valores pelos quais se rege a associação?

3) A associação parece voltada para o passado, para o presente ou para o futuro? Como se exprime essa orientação?

4) Quais os projetos futuro da associação?

As perguntas para o grupo de enfermeiros foram: Como você percebe a inserção da Enfermagem no contexto organizacional? Qual a missão do Serviço de Enfermagem? Como se dá o processo de socialização dos novos membros? Quais os benefícios oferecidos aos enfermeiros pela instituição? Existe algum tipo de incentivo para o aprimoramento profissional? Com quais setores da instituição é mais difícil para a Enfermagem se relacionar? Porque? O grupo de enfermeiros é coeso em seus objetivos?

As entrevistas foram realizadas pelos pesquisadores, gravadas com consentimento do grupo de entrevistados e posteriormente transcritas para a efetuação da análise.

Para desvelar traços da cultura profissional do Serviço de Enfermagem, utilizou-se o recurso de entrevista diretiva ${ }^{(5)}$ para desvendar as crenças, valores e pressupostos básicos que norteiam a prática profissional.

\section{Caracterização da Empresa}

\section{Histórico de Vida Profissional do Fundador}

A vida profissional do fundador revela-o

como homem de ampla cultura e médico de rara sensibilidade, notável pelos seus diagnósticos e indicações cirúrgicas precisas. Ainda jovem, alcançou lugar de destaque na Ortopedia Nacional, tendo sido um dos sócios fundadores da Sociedade Brasileira de Ortopedia e Traumatologia. Incansável na busca de novos conhecimentos foi um dos primeiros brasileiros a se especializar em Ortopedia e Traumatologia no exterior. Fez cursos na Itália, na Áustria e nos Estados Unidos.

Em 1935 começou a trabalhar na Santa Casa de Misericórdia de São Paulo ajudando, de forma decisiva, a formar uma escola ortopédica que deu e continua dando a São Paulo e, ao Brasil, excelentes especialistas.

Já naquela época, mostrava facetas do seu caráter que marcariam toda sua vida: o perfeccionismo, a exigência na observação do detalhe o "visum et repertum" como dizia ele, o respeito ao paciente, a honestidade científica, a crítica dura e às vezes até áspera, porém jamais injusta.

Na década de 40, começou a se preocupar com a sorte do deficiente físico que tinha alta dos ambulatórios de ortopedia.Em sua maioria, os pacientes saiam do hospital com dificuldades motoras expressivas e, também, com sérias dificuldades econômicas que dificultavam o retorno ao núcleo familiar e social.

Em 1944, descobriu um livro "The crippled child in New York City" - "A criança defeituosa em Nova York", e impressionouse com a organização dos serviços de reabilitação norte americano motivando-o a idealizar serviço semelhante na cidade de São Paulo. Nascendo, daí, a idéia de construir um Centro de Reabilitação.

Sua força era o idealismo, a certeza de estar ao lado da verdade, a certeza de estar navegando para descobrir um novo mundo, um mundo para o deficiente físico. Tinha o dom e a coragem de transformar os seus sonhos e as suas idéias em realidade.

Seu trabalho foi reconhecido, internacionalmente, quando em 1964 recebeu na Dinamarca o prêmio internacional "Albert Lasker", outorgado somente a homens que contribuíram, mundialmente, para o progresso da Reabilitação.

Trabalhou muito e lutou arduamente durante toda a sua vida e morreu subitamente
O processo de formação de cultura organizacional em um hospital filantrópico 
Valéria Bertonha Machado Paulina Kurcgant em 1976 quando planejava a construção de um centro cirúrgico para a instituição.

\section{Histórico da Instituição}

A instituição foi legalmente formalizada em 3 de agosto de 1950, concretizando assim o sonho de seu fundador, que para realizá-lo arregimentou amigos e sensibilizou autoridades.

$\mathrm{Na}$ assembléia de fundação foi votado o estatuto e realizada a eleição dos membros do conselho administrativo, composto por 33 pessoas, entre elas 9 do sexo feminino.

Os objetivos da instituição visavam proporcionar atendimento, reabilitação, educação e reinserção social e, para tanto, muito trabalho foi, incansavelmente realizado.

A instituição teve seu início em uma sala cedida no pavilhão Fernandinho na Santa Casa de Misericórdia de São Paulo. Assim, o conselho administrativo iniciou suas atividades com muita dificuldade, e o sonho do fundador começou a concretizar-se.

Em 1951, a Associação alugou uma casa na região central de São Paulo como sede provisória; no ano seguinte, foi inaugurado o Centro de Reabilitação e Educação, com a colaboração da ONU que enviou uma técnica norte americana (que durante muitos anos dirigiu a famosa Spalding School of Chicago) para dirigir o Centro de Educação. Este centro tinha por objetivos oferecer ensino primário às crianças $\mathrm{e}$ instrução profissional aos adolescentes com defeitos físicos, funcio-nando em regime de semi-internato. As atividades diárias dividiam-se entre as aulas, fisioterapia, reeducação muscular, iniciação na aprendizagem de alguma profissão para futura inserção no mercado de trabalho.

A questão educacional do deficiente físico foi sempre a grande preocupação do fundador desta instituição. Daí a sua afirmação:

não pode haver maior desgraça para um ser humano que além do defeito físico e da pobreza, carregar o pesado fardo da ignorância.

Além da criação deste centro educacional, batalhou para a criação de unidades de Classes Especiais para deficientes físicos em escolas do governo.
Nessa época foi contactada a empresa Philips do Brasil para a colocação dos adolescentes em serviços compatíveis com suas condições físicas. Mais recentemente, no ano de 1993, foi assinado um contrato com o sindicato dos bancos para colocação dos deficientes físicos no mercado de trabalho da área.

Em 1963 foi inaugurado o Centro de Reabilitação em sede própria construído em terreno doado pela Prefeitura de São Paulo. Para o planejamento deste centro foi enviado, ao Brasil, um arquiteto americano com ampla experiência nesta área.

$\mathrm{Na}$ época da construção do centro, a opinião de muitos era de que a execução de tal obra era irrealizável devido ao alto custo e à pequena disponibilidade financeira. $\mathrm{O}$ fundador trabalhou incansavelmente, lutou contra a descrença e a fraqueza de vários homens e com a ajuda de outros que acreditavam em suas idéias.

Após a construção do Centro, foi montada uma oficina ortopédica na instituição e se firmou, com o Fundo Mundial de Reabilitação de Nova York, um convênio no qual a instituição se encarregaria de ministrar cursos de alcance internacional, para a formação de técnicos em Aparelhos Ortopédicos e Membros Artificiais. Nesses cursos já se formaram inúmeros técnicos de diferentes cidades brasileiras, bem como de vários países.

Essa oficina ortopédica do Centro de reabilitação desenvolve e produz aparelhos ortopédicos, órteses e próteses ortopédicas, atendendo à demanda da população carente que recorre a seus serviços, e também, exporta para diversos países. É um dos departamentos da instituição que muito orgulha a administração por ser o maior centro de, pesquisas e tecnologia, gerando receita e mantendo-se com recursos próprios.

Desde a fundação da instituição, a idéia de se construir um centro cirúrgico estava presente, porém sempre esbarrava na escassez de recursos financeiros. A estrutura médico social do país ainda deixava muito a desejar. Estávamos em meio à fase de uma medicina estritamente curativa, enquanto os países mais desenvolvidos já a ultrapassaram, fazendo uso da medicina preventiva, menos dispendiosa, mais eficiente e mais humana.

Era fato concreto que todo paciente portador de deficiência física, um dia deveria 
recorrer a um Centro de Reabilitação para tratamento. Infelizmente, a grande maioria desses pacientes procurava recuperação já com seqüelas graves da moléstia necessitando, quase sempre, de tratamento cirúrgico como parte importante e fundamental do seu processo de Reabilitação.

A previdência social na época não previa reabilitação global ao incapacitado físico (exceto para os casos de acidente de trabalho). Assim, os pacientes recorriam aos centros particulares sem fins lucrativos, como era o da instituição em estudo, ou aos centros que recebam auxílio do INAMPS.

São Paulo não tinha, até aquele momento, um Centro de Reabilitação com hospital em anexo. Quando se estava diante de um caso com indicação cirúrgica, o paciente era enviado ao INAMPS, quando tinha direito, ou para Hospitais de indigentes, surgindo então os problemas de locomoção, as filas de espera. Dentro desse esquema as crianças são examinadas segundo as normas específicas da especialidade sem a visão global da equipe de Reabilitação. Decorrente desta situação havia descontinuidade nas indicações cirúrgicas e condutas préoperatórias, operatórias e pós-operatória. Era desobedecido o princípio básico de que a equipe médica indica o tratamento, o cirurgião da equipe opera e a equipe especializada reabilita.

Assim, era essencial, para completar o circuito de atendimento, que a instituição tivesse um hospital onde pudesse realizar suas indicações cirúrgicas, além de poder desenvolver atividades acadêmicas.

Com o hospital poderiam ser desenvolvidos novos procedimentos de atendimento pelos profissionais da área técnica, visto ser extenso o número de pacientes que procurava a instituição. Com isso deixariam de ser menos seguidores de trabalhos publicados no exterior e de absorver técnicas estrangeiras, para adquirirem, pelo menos parcialmente, a independência científica.

Dessa forma, a instituição com seus antecedentes em Reabilitação, Ortopedia Infantil, Urologia, Fisiatria, Neurologia etc, estaria preparada para completar o circulo da Reabilitação Física que se inicia, em muitos casos, pelo tratamento cirúrgico e termina com a independência física.
Da idéia inicial de se criar um centro de reabilitação aonde a criança defeituosa viesse apenas para efetuar a reabilitação e estudar, a associação foi crescendo de tal forma que se fez necessário fechar o circuito de atendimento, criando o centro de diagnóstico centro de tratamento - centro de reabilitação escola - profíssionalização do deficiente físico e inserção no mercado de trabalho.

Em 12 de julho de 1993 foi inaugurado o Hospital. Tem início uma nova era na vida da organização, com a expansão não apenas da área física, mas principalmente do grau de complexidade dos procedimentos.

Atualmente a instituição possui duas unidades de reabilitação situadas em áreas estratégicas da cidade de São Paulo. A unidade Central fica localizada na região Sul e outra na região leste. No ano de 1999, inaugurou o Centro de Reabilitação na cidade de Recife, com o objetivo de descentralizar e facilitar o atendimento da população de toda a região norte e nordeste do Brasil.

Missão da Instituição: Prestar assistência aos portadores de deficiência física, empregando técnicas cientificamente comprovadas, objetivando a reabilitação de seus pacientes de forma global, visando a restituição da sua cidadania.

\section{Histórico da Inserção do Serviço de Enfermagem}

Com a inauguração do Hospital, surgiu a necessidade de buscar, no mercado, profissionais da área de Enfermagem para gerenciar e prestar assistência aos pacientes, uma vez que o centro de reabilitação contava apenas com uma enfermeira

A partir de então, tem início a formação de uma cultura profissional, com trajetória diferente das já existentes na instituição. Contrapondose aos outros grupos profissionais, os enfermeiros não "nasceram" na cultura da instituição em estudo, vieram de outras instituições com visões e vivencias diferentes.

Soma-se a este fato a formação acadê-mica do enfermeiro que em seu curso de graduação possui, na grade curricular disciplinas da área administrativa focalizando o gerenciamento da assistência e da equipe de Enfermagem e tendo como pré-requisito, para gerenciar o serviço de Enfermagem, possuir especialização em administração hospitalar.
O processo de formação de cultura organizacional em um hospital filantrópico 
Valéria Bertonha Machado Paulina Kurcgant
Devido a essa formação os enfermeiros começaram a reavaliar procedimentos administrativos, tendo início um processo de reflexão sobre a maneira de conduzir a instituição, a partir deste grupo de profissionais.

Foram sendo detectadas falhas no centro de custos e sistema de rateio entre as diferentes unidades bem como na forma de efetuar cobrança sobre os procedimentos realizados.

Com o apoio de outros profissionais da área técnica que também estavam descontentes, foi contratada uma enfermeira para realizar auditoria em todos os prontuários dos pacientes. Conseguiram também que fosse contratada uma auditoria externa para ajudálos a redesenhar o seu processo de trabalho.

O grupo de Enfermeiros assimilou, rapidamente, um pressuposto básico da instituição que é a valorização da competência técnico- científica do profissional que ali atua. Esse grupo passou a desenvolver trabalhos de pesquisa, desmistificando o dogma existente sobre a função do enfermeiro de ser apenas um profissional que presta cuidados de higiene aos pacientes, visão esta que surgiu nos primórdios da fundação da instituição, quando estes cuidados eram prestados por voluntárias. Passaram a participar das reuniões científicas que são realizadas uma vez por semana onde são discutidos casos clínicos, passando a participar efetivamente na discussão do planejamento do cuidado ao paciente.

O maior problema de relacionamento relatado foi com a equipe de fisioterapeutas, pois há uma disputa pelo cuidado ao paciente, entendendose que esses profissionais interferem no campo de atuação da equipe de Enfermagem.

Outro grande obstáculo encontrado foi o processo de comunicação com a área administrativa, problema este relatado por diferentes grupos de profissionais.

A teoria da mudança, que desenvolveu a análise do campo de forças, propõe que, embora as forças impulsionadoras possam ser mais facilmente afetadas, alterá-las poderia aumentar a oposição, tensão e ou conflito dentro da organização, acrescentando forças restritivas. Portanto, pode ser mais eficaz eliminar forças restritivas para criar a mudança.

\section{Forças Impulsionadoras:}

- Capital Humano da área técnica altamente qualificado e comprometido com a missão da instituição;

- Nível técnico focado em competência.

Forças Restritivas:

- Estrutura Organizacional;

- Organização do processo de trabalho;

- Padrões culturais e relações interpessoais;

- Visão amadora de gerenciamento(não gerar superávit?);

- Comunicação Interna e Processo decisório;

- Modelo de gestão Centralizador (muitos níveis hierárquicos);

- Visão técnica sofrendo a interferência da falta de competência gerencial.

Linhas de Ação:

- Redesenhar a estrutura organizacional de forma a torná-la mais ágil e eficiente;

- Redesenhar a organização do processo de trabalho de forma a torná-lo mais dinâmico;

- Detectar as relações conflitantes entre os membros da organização;

- Adotar modelo de gestão mais participativo;

- Descentralizar o processo decisório, criando uma visão integralizada;

- Desburocratizar a comunicação, criando meios mais eficazes para atingir os objetivos propostos;

- Adotar um modelo de gestão adequado à realidade institucional, diminuindo os níveis hierárquicos. Treinar e capacitar os profissionais para essa nova visão;

- A área técnica possui o poder do conhecimento e da competência técnica na organização, deverá discutir, com a administração superior, as decisões, dessa instância administrativa, que dificultam ou até impedem a consecução de metas do serviço de enfermagem.

\section{CONCLUSÃO}

O crescimento denominado, por muitos membros da instituição, como abrupto e traumático, está conduzindo os profissionais que gerenciam a instituição, a uma reflexão para a necessidade de mudanças na maneira de geri-la. 
Todo processo de mudança implica numa reestruturação do conhecido, naquilo que as pessoas já estavam habituadas ocasionando, nos sujeitos que estão vivenciando o processo, sentimentos de perda, gerando conflitos entre mudar ou conservar a antiga estrutura.

Há uma tênue mobilização dos profissionais da área técnica, que são a mola propulsora da organização, no sentido de exigir mudanças. Estas mudanças já estão ocorrendo de maneira lenta e pontual.

Entretanto, ao mesmo tempo em que querem a mudança, mostram uma rejeição natural ao novo, ao desconhecido, processo que leva tempo para que haja adaptação à nova situação.

As mudanças geram incertezas, transformam as relações de poder, mudam a estrutura das forças que sustentam o "status quo", e obrigam a procurar novas formas para a resolução dos conflitos que advém com a nova era.

Há de se perguntar se realmente a alta administração está disposta a enfrentar a mudança indo à raiz dos problemas, pois isso implica, muitas vezes, em perda de poder ou em redistribuição do mesmo.

O estudo mostra, também, que quando grupos ocupacionais diferentes são colocados em relação de dependência, freqüentemente geram, nas organizações, uma "guerra cultural", e finalmente evidencia que existem processos nos quais a mudança quantitativa, eventualmente, pode levar a eventos que ocasionam mudanças na qualidade.

\section{REFERÊNCIAS}

(1) Schein E. Organizational culture and leadership. San Francisco: Jossey Bass; 1986.

(2) Fleury MTL. Cultura e poder nas organizações. 2 a ed. São Paulo: Atlas; 1996.

(3) Thevenét M. Cultura de empresa, auditoria e mudança. Lisboa: Monitor; 1989.
(4) Bateman TS, Snell SA. Administração construindo vantagem competitiva. São Paulo: Atlas; 1998.

(5) Trivinõs ANS. Introdução á pesquisa em ciências sociais.São Paulo: Atlas; 1987.
O processo de formação de cultura organizacional em um hospital filantrópico 